\title{
COMMUNITY PEOPLE PREPAREDNESS AND RESPONSE ON PREVENTION AND CONTROL OF COVID-19 BEST PRACTICE IN BANGLADESH
}

\author{
Bimal Chandra Das', Sahedul Islam Bhuiyan², A S M Wali Ullah³, Muhammad Zahangir \\ Alam³, Gazi Golam Mostofa33, Khondaker Zahirul Hasan³. Sohel Sarwar', Reaz Uddin \\ Chowdhury5, Joya Paul6, AKM Mahbubul Haque7, Mohammad Shamsal Islam8, \\ Mohammed Alauddin?
}
1. Associate Professor, Abdul Malek Ukil Medical College and Hospital, Bangladesh
2. Professor, Brahmanbaria Medical College and Hospital, Bangladesh
3. Assistant Professor, Abdul Malek Ukil Medical College and Hospital, Bangladesh
4. Assistant Registrar, Abdul Malek Ukil Medical College and Hospital, Bangladesh
5. Consultant Internist, Abdul Malek Ukil Medical College and Hospital, Bangladesh
6. Consultant, Upasham General Hospital Feni, Bangladesh
7. Managing Director, Konika Consulting services Pvt Itd, Bangladesh
8. Research Consultant and Data Analyst, Orbis International, Bangladesh
9. PhD candidate, Bangladesh University of Professionals (BUP), Bangladesh

Correspondence: drbimalcmc28@gmail.com

\section{ABSTRACT}

\section{PURPOSE:}

The major objectives of the study were to assess the knowledge, attitude \& practice (KAP) towards community preparedness and response on prevention of COVID-19 among the community.

\section{METHOD:}

A sample survey was conducted to collect data from people admitted in a district level tertiary hospital for treatment of various health complications during COVID-19 pandemic. A total of 300 randomly selected patients and their attendants were interviewed in the hospital setting.

\section{RESULTS:}

The mean knowledge score was 18.73 out of 24 and the main sources of information were TV (86.5\%), radio (13\%), newspaper (13\%), social media (13.5\%), friends/relatives
(14\%), formal healthcare providers (6\%) and religious leaders (3\%). Knowledge was significantly poor among aged people, women, less educated and those on low incomes. The Majority of participants (79\%) suggested wearing facemasks as effective tools to prevent COVID-19 from spreading, $56 \%$ mentioned maintaining of physical or social distance as crucial to prevent the infection. We found strong relationship between monthly total family expenses and wearing of facemasks by gender to prevent the COVID-19 ( $\mathrm{x} 2=18.405$; Cramer's $\mathrm{V}=.17$, $\mathrm{df}=8$; sig; $\mathrm{P}=<$ .018). Similarly maintaining physical/social distance to prevent COVID-19 is also related to respondents' economic strata $(x 2=43.741$; Cramer's $V=.14$, df = 20; Sig; $P=<.002)$.

\section{CONCLUSIONS:}

An awareness program on COVID-19 is very important to prevent the spread of the virus. Effective communication intervention with increasing treatment facilities is essential 
for prevention and control of COVID-19. Government and development agencies should prioritize the COVID-19 response program with regular health care services.

\section{KEYWORDS}

COVID-19, KAP, community mitigation, preparedness, response, Bangladesh

\section{INTRODUCTION}

Poor hygienic practices, inadequate water supply and poor sanitary conditions play a major role in the spread of infectious diseases. Lack of Knowledge, Attitude and Practices (KAP) on Water, Sanitation and Hygiene (WASH) is one of the most imperative causes for transmission of diseases. Population density, poor health systems and unpredictable COVID-19 made the situation worse for a lower-middle income country like Bangladesh. Active surveillance, early detection, isolation and case management, contact tracing and prevention of onward spread and overall people's knowledge about preparedness and response are very crucial to control an infectious disease such as COVID-19. Evidence shows that ability to effectively respond to unpredictable infectious diseases mostly depends on people's knowledge about it and preparedness for prevention and mitigation measures.[1] Community engagement and practical knowledge on preparedness planning are vital factors to reduce the burden associated with the health threat in terms of mortality and morbidity, hospitalizations and demand for health care goods and services; to maintain essential services, protect vulnerable groups, minimize economic loss and social disturbance and enable a quick return to normal conditions. [2]

Bangladesh is a country with high population-density. Around $63.4 \%$ of total population in 2018 lived in rural areas.

[3] About 3\% of Bangladesh's GDP is spent on health, out of which the government contribution is about $1.1 \%$. In term of dollar, the total health expenditure in the country is about US\$12 per capita per annum, of which the public health expenditure is around US\$ 4. [4] A large number of Bangladeshi people work abroad and as a result Bangladesh faces the risk of virus importation and its onward transmission. So the goal of the study is to understand the level of KAP on COVID-19 among the community people residing in and around Noakhali district regarding their preparedness and response on prevention and control of COVID-19.

\section{MATERIALS AND METHODS}

A cross-sectional descriptive study was conducted to collect data from patients and their attendants at Abdul Malek Ukil Medical College and Hospital in Noakhali district in the southern part of Bangladesh. The study was conducted in May and June 2020. Following a standard formula for determination of a representative sample size, and our desired sample size was 291 and we acheived 300. Initially we had planned to collect data from one government hospital and one private hospital but due to the severity of COVID-19, we had to change our plan and collect data only from the government-run medical college and hospital.

We interviewed patients and their attendants aged 18 years or above who visited the hospital in May and June 2020 during COVID-19 pandemic. In order to get our desired respondents from the hospital setting during COVID-19 pandemic we had arranged a formal session for intern doctors. There was a high refusal rate of response due to panic situation of COVID-19 and finally, a total 300 respondents were interviewed. Sampling includes both males and females.

\section{DATA COLLECTION, QUALITY CONTROL, DATA PROCESSING AND ANALYSIS:}

A structured interview schedule was prepared incorporating the following variables: socio-economic and demographic conditions of respondents, and their KAP, preparedness and response about COVID-19. The interview schedule was filled-in by trained interviewers chosen intern doctors. There were both open and close-ended questions in the interview schedule. A total of 36 questions in four parts were asked to collect data from respondents.

In section C10 questions were asked regarding Knowledge, Attitude and Practice (KAP) related to COVID-19 prevention and control. In this section, each question was scored as ' 0 ' for incorrect answer and ' 1 ' for correct answer. Those who received scores of 0-5 were classified as having "poor" knowledge; those with scores of 6-8 were classified as "moderate", while those scoring 9-10 were graded as "good". Same techniques were also applied to measure respondent's attitude and practice on COVID-19 pandemic. [5]

A technical research team headed by an associate professor at the same medical college and hospital led the process of development of research instruments and data 
collection. The developed interview schedule was tested for reliability and validity. The item objective congruence technique was used for detecting validity. We remained alert about the quality of data. There was a one-day virtual session with all persons involved with the study for clear understanding of the study goal and every question of interview schedule.

Consistency of data was checked by a public health expert. The study format and interview schedule were given to an expert team (epidemiologist, public health practitioner and medical doctor) for determining content validity. Their comments were incorporated in final research instruments. The respondents were asked to participate in the study voluntarily. Those who agreed to participate in the study were requested to sign the consent form. The filled-in schedules were checked and edited immediately after the collection. Again, data were cleaned before analysis. Both univariate and bivariate tables are generated during analysis. Statistics used are frequency distribution, measurement of central tendency (mean, median, and mode) measures of dispersion (Standard deviation), and non-parametric tests (Chisquare, Cramer's V). The level of significance used was at 0.05 .

\section{ETHICAL CONSIDERATION:}

The ethical review committee at the Dr. Abdul Malek
Medical College \& Hospital approved the proposal.

\section{RESULTS}

\section{SOCIO-DEMOGRAPHIC CHARACTERISTICS:}

The study revealed that apparently a large number of patients and their attendants aged between 18 to 35 years, nearly two-thirds (76\%) visited the hospital to get admitted for treatment as patients or their attendants during COVID19 pandemic. Among them, 83\% were female and $66 \%$ were male. $17 \%$ of the total patients and their attendants aged between 36 and 45 years - male $27.5 \%$ and female $9 \%$. Only a few $(7 \%)$ of the total patients and their attendants (male $6 \%$ and female $8 \%$ ) visited hospital for same reasons. The mean age of total patients and their attendants interviewed were 30.52 years (male 30 years and female 31 years) but median age was around 28.80 years for both, which indicated a large number of patients and their attendants were young adults and few were elderly. The most interesting fact is that majority respondents (around 90\%) of the total interviewed were in young adults ranging from 18 and 40 years (Table-1), which means that young adults are more enthusiastic than elderly peoples to visit hospital for treatment or taking care of family members during health emergency such as COVID19 pandemic.

\section{TABLE1: PERCENTAGE DISTRIBUTION OF AGE OF THE RESPONDENTS BY GENDER}

\begin{tabular}{|l|l|l|l|}
\hline Age Categories & $\begin{array}{l}\text { Male } \\
\mathbf{n}=140\end{array}$ & $\begin{array}{l}\text { Female } \\
\mathbf{n}=160\end{array}$ & $\begin{array}{l}\text { Total } \\
\mathbf{n}=300\end{array}$ \\
\cline { 2 - 4 } & Percentage & Percentage & Percentage \\
\hline $18-22$ years & $8.5 \%$ & $30 \%$ & $20 \%$ \\
\hline $23-30$ years & $34 \%$ & $39 \%$ & $37 \%$ \\
\hline $31-35$ years & $24 \%$ & $14 \%$ & $19 \%$ \\
\hline $36-40$ years & $20 \%$ & $6 \%$ & $13 \%$ \\
\hline $41-45$ years & $7.5 \%$ & $3 \%$ & $4 \%$ \\
\hline $46-90$ years & $6 \%$ & $8 \%$ & $7 \%$ \\
\hline Total & 100.0 & 100.0 & 100.0 \\
\hline Mean & 30.01 & 30.96 & 30.52 \\
\hline Median & 28.90 & 28.70 & 28.80 \\
\hline St. deviation & 9.76 & 8.91 & 9.33 \\
\hline$x^{2}=31.183 ;$ Cramer's V $=.48, \mathrm{df}=6 ;$ Sig; P=<.001 & \\
\hline
\end{tabular}


Respondents age differences by gender was found statistically significant at .001 level $(x 2=31.183$; Cramer's $V=$ .48 , df $=6$ ) (Table-1). The study included both male and female respondents but the number of female respondents was slightly higher (53\%) than the male respondents (47\%) which indicate that females are more inclined in visiting hospital as patients or their attendants compared to their male counterparts.

FIGURE 1: PERCENTAGE DISTRIBUTION OF OCCUPATION OF THE RESPONDENTS

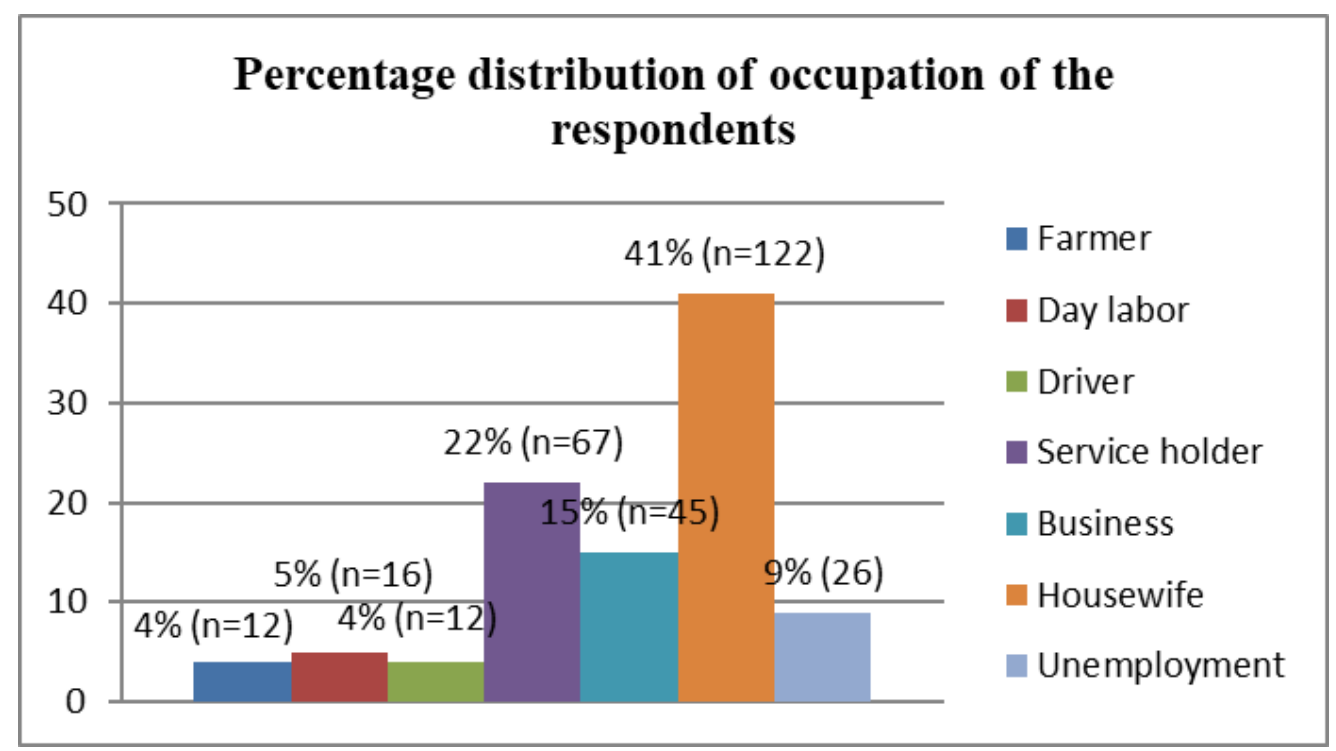

The study also revealed that around 9\% respondents were illiterate, $11 \%$ completed up to primary level, $21 \%$ up to secondary level and only $11 \%$ completed their graduation level $(x 2=31.183$; Cramer's $\mathrm{V}=.48, \mathrm{df}=6$; Sig; $\mathrm{P}=<.001)$. Most common occupations among the respondents were housewife (41\%), service holder (22\%), businesspeople (15\%), unemployment (9\%), farmer (4\%) and day laborer (4\%) (Figure-1). Most of the respondents were married $(88.4 \%)$ and $11 \%$ were single while $97 \%$ of the household heads were male and $3 \%$ female.

The average monthly total income was 22,752 BDT (274 US dollar) whereas total monthly expenses were 17,378 BDT (210 US dollar). This figure is slightly higher compared to national average household income. Possibly it was because of the fact that data was collected from district level hospital and sub-urban location, where middle-class and upper class people live in and the majority of the respondents' household heads work as immigrants outside the country. Patients and their attendants seemed to have come for services on an average from a distance of 12 kilometres and median distance indicates that more than half of the patients and their attendants came to hospital from within 7 kilometres. This means a large percentage of inner-city patients utilize the hospital services compared to those from outside the city during COVID-19 pandemic.

\section{PATTERN OF PREPAREDNESS AND RESPONSE TO COVID-19:}

The persisting COVID-19 is a big public health concern all over the world and Bangladesh is facing catastrophic health problem due to inadequate and unplanned health system. There is ongoing debate whether government measures are adequate for the control of COVID-19 pandemic or not.

Bangladesh has confirmed it first COVID-19 case on March 8, 2020, though many experts speculated that the virus might have entered the country much earlier but had not been detected due to inadequate monitoring. [6] The government of Bangladesh has taken many measures to prevent COVID-19 and the country has been under lockdown (general holidays) for 66-days since March 26, 2020.

In response to a question on perception of the COVID-19, around $99 \%$ of the respondents heard about COVID-19 while $86.5 \%$ knew it from television followed by radio (13.1\%), newspaper (13.1\%), social media (13.5\%), religious leaders (3.1\%), friends/relatives (14\%) and formal healthcare providers (6\%) as described in Figure-2 below. A strong relationship is found between age of respondents and sources of information. The formal sources of information obtained by respondents progressively 
increase with the increase of their age $(x 2=72.068$; Cramer's $V=.42$, df $=45$; Sig; $P=<.006$ ). Possible reasons could be that relatively older people chose to stay at home due to COVID-19 and were more likely to watch TV, follow radio programs and read newspaper to get updates on COVID-19 pandemic while passing time at home. A positive relationship is also found between the total monthly family income \& expenses, respondent's gender, occupation, gender of household head, marital status, ownership of home and getting updates on COVID-19 (x2= 111.08; Cramer's $V=.43$, $\mathrm{df}=70$; Sig; $\mathrm{P}=<.001$ ).

FIGURE 2: PERCENTAGE DISTRIBUTION OF SOURCES OF INFORMATION ABOUT COVID-19

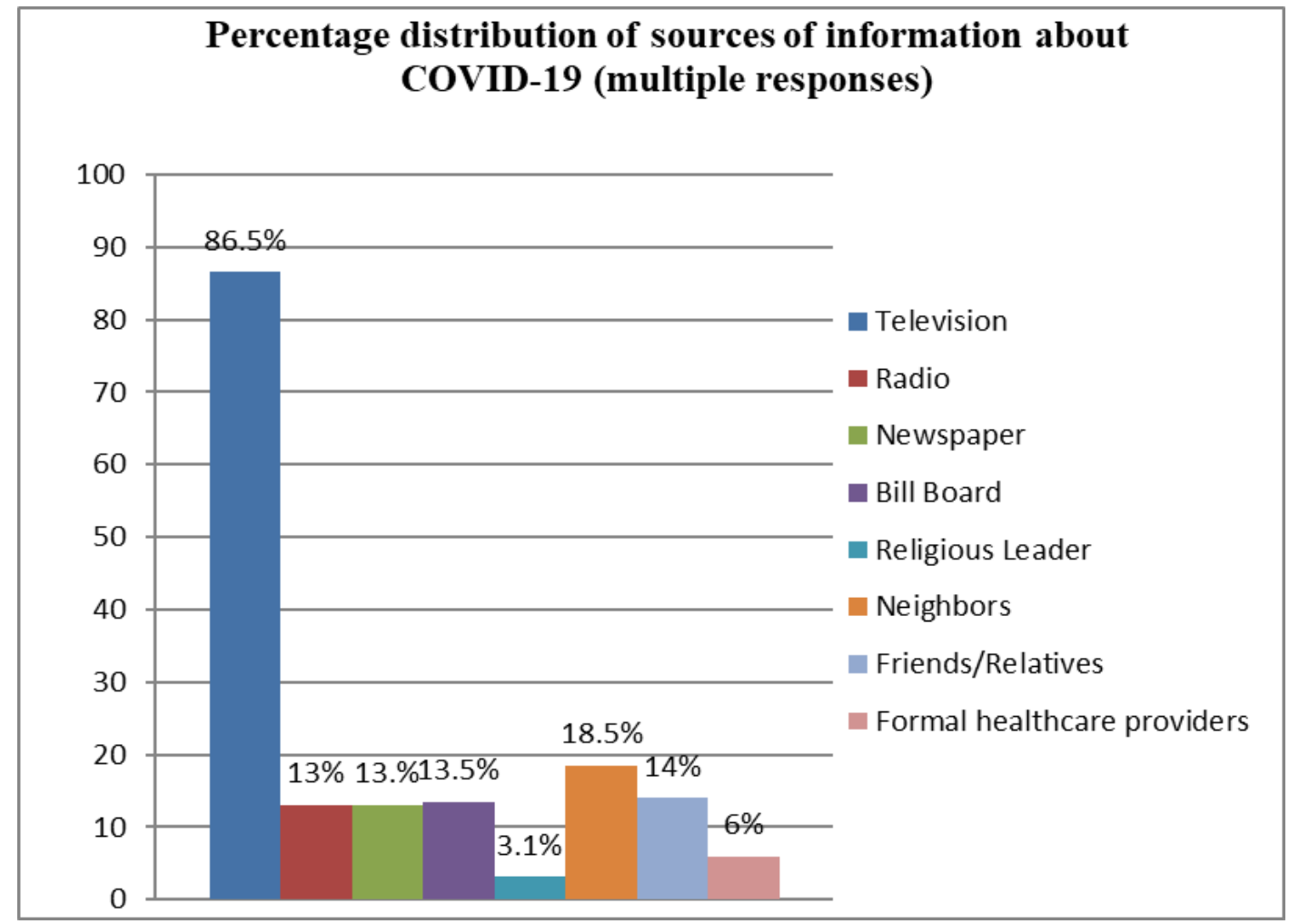

FIGURE 3: PERCENTAGE DISTRIBUTION OF TYPE OF SERVICES RECEIVED BY RESPONDENTS DURING COVID-19

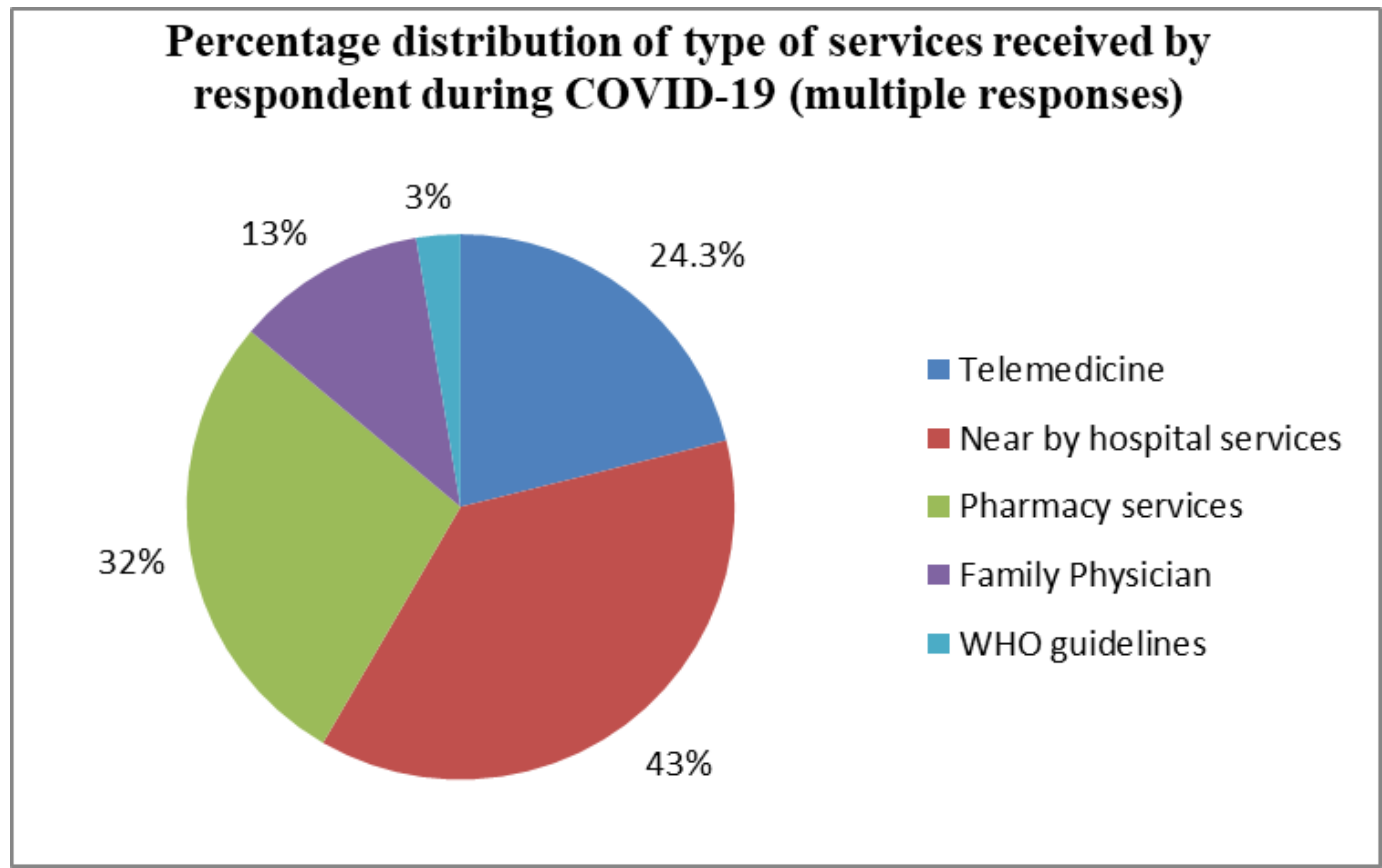


The striking feature here is that about $79 \%$ of the respondents wear facemasks as an effective tool to prevent COVID-19, whereas $63 \%$ preferred maintaining physical distance or social distance and $15 \%$ home quarantine.

The World Health Organization (WHO) has released an updated version [7] which includes a section on advice to decision makers on the use of facemasks for all people in community setting and we found strong relationship between monthly total family expenses and using of facemasks to prevent the COVID-19 (x2=18.405; Cramer's $\mathrm{V}=.17, \mathrm{df}=8 ; \mathrm{Sig} ; \mathrm{P}=<.018)$. We found that the use of facemasks by respondents increases with their economic condition and irrespective of gender. Similarly maintaining physical distance to prevent COVID-19 is also related to respondents' economic strata ( $x 2=43.741$; Cramer's $V=.14$, $\mathrm{df}=20$; Sig; $\mathrm{P}=<.002$ ). The most interesting fact is that maintaining physical distance or social distance to prevent COVID-19 is strongly correlated with respondents' religion $(x 2=13.719 ;$ Cramer's $V=.12, d f=6$; Sig; $P=<.008)$.

Interestingly, we have observed poor knowledge of respondents about actual distance recommended for maintaining the physical distance. Around $88 \%$ respondents said that they have to keep distance of 1-2 metres to prevent COVID-19 whereas $12 \%$ had mentioned 3 metres' distance. However, majority of the respondents (77\%) had good knowledge on systematic way such as following doctor's advice, and WHO guidelines and rules of isolation for preventing COVID-19. About $26 \%$ of respondents had faced various difficulties in receiving treatment during COVID-19. Among them 65\% faced difficulty in getting doctor's appointment, $32 \%$ had troubles in getting diagnosis of diseases, and $17 \%$ could not travel for treatment and $10 \%$ faced difficulty buying medicine as described in Figure-3. We observed relationship between type of treatment received during COVID-19 and respondent's level of education, distance from hospital, gender of household head and monthly total family expenses $(\times 2=16.537$; Cramer's $V=.32$, df $=11$; Sig; $P=<$ $.005)$.

\section{DISCUSSION}

The study had three goals; first to make a quick assessment of knowledge, attitude and practice, second to determine people's preparedness on COVID-19, and third to understand the level of response to COVID-19 at district level as well as sub-urban setting. Although we had interviewed both males and females, they significantly differed in age structure. The mean ages of male and female patients and their attendants were around 30 years, but median ages were only 31 years for both, which means a large number of respondents were young adults and few were elderly. The probable explanation can be that young adults are possibly more enthusiastic than the elderly to visit hospitals for receiving health related services or caring for their family members during COVID-19 pandemic. COVID19 outbreak first identified in Wuhan, China in December [8] and in Bangladesh first COVID-19 case was identified at Satkhira district in Khulna division on March 8, 2020. [9]

The disease had spread in more than 210 countries with a mortality rate of about $5.7 \%$ whereas in Bangladesh it was 1.38. [10] Bangladesh is a country with high populationdensity. Around $63.4 \%$ of total population in 2018 lived in rural areas. The high density of population could be associated with a great risk of spread and mortality, especially during seeking treatment at district level hospital. For this reason we had conducted this study to understand the pattern of KAP of the community and their preparedness and response to COVID-19. The government of Bangladesh and other development partners are working together to improve the awareness of general people about the disease and reduce the mortality and morbidity. The people who live at district level of southern part of Bangladesh were very close to the spread of COVID-19 because most of the household heads work outside the country and that time they had frequently travelled from COVID-19 infected countries. As a result the family members and neighbors were become vulnerable to COVID-19 infection, particularly those who have poor knowledge, attitudes, and low preparedness skills to engage in COVID-19 prevention and control.

COVID-19 was very much an unknown disease to people of rural and remote areas, and World Health Organization changed their recommendations very frequently due to changing DNA of COVID-19. From this point of view KAP and preparedness and level of response of community people become an important issue in the context of public health. The WHO suggested it member countries to improve the knowledge of communities on the care and diagnosis of COVID-19, especially optimizing the use of protective equipment and other infection prevention and control measures in health care and community settings. [11] There is ongoing debate about government steps to control the COVID-19 in Bangladesh and the country 
started it lockdown measures since March 26, 2020. As a result, people become aware about it and our study found that around $99 \%$ have heard about COVID-19.

Our result is supported by another online study conducted by Australian Western Sydney University and Begum Rokeya University, Rangpur, Bangladesh [12] and they found that around $99 \%$ Bangladeshi people have heard about COVID-19 and most of them heard about it from formal print and electronic channel such as TV and social media. [13] The interesting fact is that sources of information and people's knowledge have strong relationship, and as a result the mortality rate is low in Bangladesh compared to developed countries. [14] In our study we found that $79 \%$ respondents suggested the use of facemasks as effective tools to prevent COVID-19 and our study finding was strongly supported by $\mathrm{WHO}$ and other countries scientific publications. [15] We found that the use of facemasks by respondents increases with their economic condition and irrespective of gender. Similarly maintaining physical distance to prevent COVID-19 is also related to respondents' economic strata. The big concern is that $63 \%$ suggested for physical distance/social distance and $15 \%$ mentioned home quarantine. This figure indicates that a low socio-economic condition does not allow people to stay at home as they have to struggle daily in a poor resource setting. Our result shows that maintaining physical distance to prevent COVID-19 is strong correlated with respondents' religion. This was a very new finding for a KAP study of such infectious diseases.

The majority of community people have poor knowledge about physical distance and we found that around $88 \%$ had no clear idea about actual distance that will help to prevent COVID-19. The most important fact is that community people's level of education, poverty, gender of household head and economic strata still plays an important role on infectious diseases prevention and control strategy. [16] In COVID-9 pandemic situation people have to struggle for getting appointment of doctor, diagnosis of diseases, and travel for treatment and buying their daily medicine.

Our study observed that treatment received during COVID19 and respondent's level of education, distance of hospital, gender of household head and monthly total family expenses are associated with difficulty of getting emergency health services like COVID-19. Social distancing is very crucial to prevent spreading the COVID-19 but our study found that only $12 \%$ people have correct knowledge about it. This could be because people in highly densely populated areas cannot afford social distance as poverty pushes them to visit their neighbors for receiving daily essential support during COVID-19 situation.

\section{CONCLUSIONS}

In general the knowledge, attitude and practice, preparedness and level of response of community people to COVID-19 are good. The people who attend at tertiary level hospital had a positive attitude toward protective measures such as using facemasks and maintaining physical or social distance, which is important to limit the spread of COVID-19. Coronavirus is global health problem and the WHO declared it a global health emergency. From this point of view, we believe that mass awareness and treatment are very important to prevent COVID-19 from spreading further in Bangladesh. An effective, accurate communication intervention with updated information is essential for prevention and control of COVID-19. Government and other development agencies should prioritize the COVID-19 response program with regular health care services.

\section{ACKNOWLEDGEMENTS:}

We like to thank to all respondents for providing essential information. We also would like to thank Abdul Malek Ukil Medical College and Hospital authority for their support in conducting this study.

\section{References:}

1. World Health Organization (2020): National Preparedness and Response Plan for COVID-19, Bangladesh Version 6. Available at; https://fscluster.org/bangladesh/document/natio nal-preparedness-and-response-plan

2. World Health Organization (2020): Coronavirus disease (COVID-19) Weekly Epidemiological Update and Weekly Operational Update https://www.who.int/emergencies/diseases/novelcoronavirus-2019/situation-reports

3. National Preparedness and Response Plan for COVID-19, Bangladesh; Government of the People's Republic of Bangladesh, Version 5, March 2020 
4. Minhazur Rahman Rezvi (2019) Health financing in Bangladesh: scarcity and its impacts. South Asia Journal September 21, 2019

http://southasiajournal.net/health-financing-inbangladesh-scarcity-and-its-impacts/

5. Srichan, Peeradone \& Apidechkul, Tawatchai \& Tamornpark, Ratipark \& Yeemard, Fartima \& Khunthason, Siriyaporn \& Kitchanapaiboon, Siwarak \& Wongnuch, Pilasinee \& Wongphaet, Asamaphon \& Upala, Panupong. (2020). Knowledge, Attitude and Preparedness to Respond to the 2019 Novel Coronavirus (COVID19) Among the Bordered Population of Northern Thailand in the Early Period of the Outbreak: A Cross-Sectional Study. SSRN Electronic Journal. $10.2139 /$ ssrn. 3546046.

6. Anwar, S., Nasrullah, M., \& Hosen, M. J. (2020). COVID-19 and Bangladesh: Challenges and How to Address Them. Frontiers in public health, 8, 154. https://doi.org/10.3389/fpubh.2020.00154

7. $\mathrm{WHO}$ interim guidance; 5 June 2020

8. Zhu, H., Wei, L., \& Niu, P. (2020). The novel coronavirus outbreak in Wuhan, China. Global health research and policy, 5, 6 . https://doi.org/10.1186/s41256-020-00135-6

9. World Health Organization situation report Bangladesh-18, June 29, 2020

10. Centre for Evidence-Based Medicine (2020) Global Covid-19 Case Fatality Rates. https://www.cebm.net/covid-19/global-covid-19case-fatality-rates/

11. Report of the WHO-China Joint Mission on Coronavirus Disease 2019 (COVID-19). 16-24 February 2020. [Accessed 7 April 2020] Available at URL: https://www.who.int/docs/defaultsource/coronaviruse/who-china-joint-mission-oncovid-19-final-report.pdf

12. Abir, Tanvir \& Kalimullah, Nazmul \& Levi Osuagwu, Uchechukwu \& Dewan, \& Nur A Yazdani, Dewan \& Husain, Taha \& Basak, Palash \& Permarupan, P.Yukthamarani \& Agho, Kingsley. (2020). Factors associated with the perception of risk and knowledge of contracting the 2019-CoV among adults in Bangladesh: Analysis of online surveys. 10.13140/RG.2.2.15130.67526.
13. 99pc Bangladeshi respondents aware of Covid-19: survey. https://tbsnews.net/coronaviruschronicle/covid-19-bangladesh/99pcbangladeshi-respondents-aware-covid-19-survey64153

14. WHO situation report June 20,2020

15. World Health Organization. Modes of transmission of virus causing COVID-19: implications for IPC precaution recommendations. www.who.int/newsroom/commentaries/detail/modes-oftransmission-of-virus-causing-covid-19-implicationsfor-ipc-precaution-recommendations.

16. Day M. Covid-19: identifying and isolating asymptomatic people helped eliminate virus in Italian village. BMJ 2020; 368: $\mathrm{m} 1165$. doi:10.1136/bmj.m1 165 